\title{
EFFICIENCY TESTING OF ELECTRIC ROTARY ACTUATORS WITH NON-STANDARD REDUCTION UNITS FOR LOWER LIMB EXOSKELETONS
}

\author{
Vladimir Belogusev*, Aleksey Egorov \\ Volga State University of Technology, Russian Federation
}

The purpose of this paper is to develop a method and instruments for identifying the efficiency of an electric rotary actuator for an electromechanical orthosis of a lower limb exoskeleton, which greatly influences its weight and dimensions. The reduction units currently used as part of electric drives for exoskeletons are made in accordance with a non-standard form factor design, which impedes the use of existing methods and tools for measuring their torque and performance without considerable errors caused by mechanical losses in the bearing assemblies of test equipment. The method proposed in this paper solves this problem by identifying the values of decelerating torque associated with friction between bearing elements. In the experimental part of this work, the proposed method and the measuring system were evaluated, and it was found that the measurement error was about $1.2 \%$, which slightly exceeds the total level of random and systematic errors of instruments applied when measuring the desired values. On the basis of the obtained results, it is possible to conclude that the developed method can be used to control the efficiency of electric rotary actuators for exoskeletons both at the stage of their production and during their operation.

Key words: electric drives performance, exoskeleton actuators, bearing losses, exoskeleton efficiency control, reducer efficiency

\section{INTRODUCTION}

Nowadays, the development of mechanisms with movable joints of links, which facilitate the movement of a human being to solve both rehabilitation and professional tasks, is receiving increased attention in the world of science and technology [1, 2, 3]. Exoskeletons allow people to perform energy-intensive tasks with reduced labor costs $[4,5,6]$. For medical purposes, the considered mechanisms provide short time for the recovery of the functions of the human musculoskeletal system [7, 8, 9]. However, on the way to making such systems, a number of problems arise, which relate to the rigidity of exoskeleton, its control, autonomy, and weight and size properties $[10,11]$. Special attention in solving the latter problem is given to the development of actuators of a high power level at low values of their weight and overall dimensions [2, 12]. Standard hydraulic cylinders are powerful enough and are able to work with high precision, but they are too heavy and require a huge number of hoses and tubes $[13,14]$. Pneumatic actuators, on the other hand, are too unpredictable in terms of handling movements, since compressed gas creates an increased level of vibration [15].

Preference is currently given to electric actuators on an electronic basis, which use magnets and provide responsive movements, as well as have great potential for lower values of weight and size $[6,12,16]$. One of the ways to create electric drives with improved torque and power density is to increase their efficiency, which will allow using the energy with less power loss caused by the resistance forces in the friction nodes of the system.
In addition, lowering the level of friction allows reducing the rate of degradation processes, such as wear and back-to-back endurance, which have a significant impact on the service life of the mechanical system [17, 18]. Thus, the efficiency of electric actuators for exoskeletons is one of the main indicators of not only their ability to provide the user with a sufficient level of power at low weight and overall dimensions values, but also the quality of their manufacture and the reliability.

Creating and maintaining high-performance electric actuators with reduction units in satisfactory condition, in turn, requires the use of methods and instruments for measuring their efficiency and torque with increased accuracy and labor efficiency, which will allow an assessment of the technical condition of the system not only at the time of its manufacturing but also during its operation. However, many exoskeletons, including the exoskeleton designed at the Volga State University of Technology together with the JSC Volga Electromechanical Plant, use reduction units of non-standard design [19]. For these units, the use of existing methods and tools for high-precision identification of torque and efficiency is impossible due to the need to install additional bearing units to support the output link of a reducer, which increases the measurement errors caused by friction between their elements [20, 21, 22]. Therefore, researches aimed at developing highly accurate, reliable and economically viable methods and instruments for monitoring the performance of electric drives with reduction units for exoskeletons are relevant.

The purpose of this paper is to develop and experimentally evaluate the method and tools for determining the 
efficiency of electric rotary actuators with reduction units of non-standard design on the basis of an electric rotary actuator for an electromechanical orthosis of a lower limb exoskeleton, which allow higher-precision measurements with low level of time and labor costs.

\section{THEORY AND METHODS}

\section{Determination of the output shaft torque of an electric rotary actuator, taking into account losses in the bearing assemblies}

Fig. 1 shows the setup for measuring the output shaft torque of an electric rotary actuator with a reduction unit for an electromechanical orthosis of a lower limb exoskeleton.

1 is a brake disk; 2 is a shaft; 3 is a torque sensor; 4 is a bearing unit; 5 is a special interconnecting link; 6 is an electric rotary actuator with a reduction unit of non-standard design.

This scheme explains the first stage of the methodology for determining the efficiency of an electric rotary actuator with a reduction unit.
According to the presented scheme, the torque is determined with the help of a high-precision tensometric torque sensor 3 , the software of which registers the torque change of an electric drive 6 in real time. The output link of a reducer is connected with the main shaft of the test bench 2 with the help of a special interconnecting link 5. The moment of resistance in the test bench is created by standard elements of the braking system for a vehicle: the bolt (the brake control lever) is tightened, and pressure on the piston of the brake master cylinder is created. The piston creates pressure in the brake master cylinder, which is transmitted through the brake hose to the caliper piston. It, in turn, presses the brake disc 1 by means of brake linings, which creates the moment of resistance on the output link of the electric drive.

The measurement is reduced to the determination of the torque, $\mathrm{M}_{\mathrm{TS}}$, when the moment of resistance reaches the value ensuring the appearance of the rated current in the motor windings. At the rated values of speed and current of the electric actuator, the output shaft torque is determined with the help of the tensometric torque sensor 3 , taking into account losses in the bearing assemblies 4.

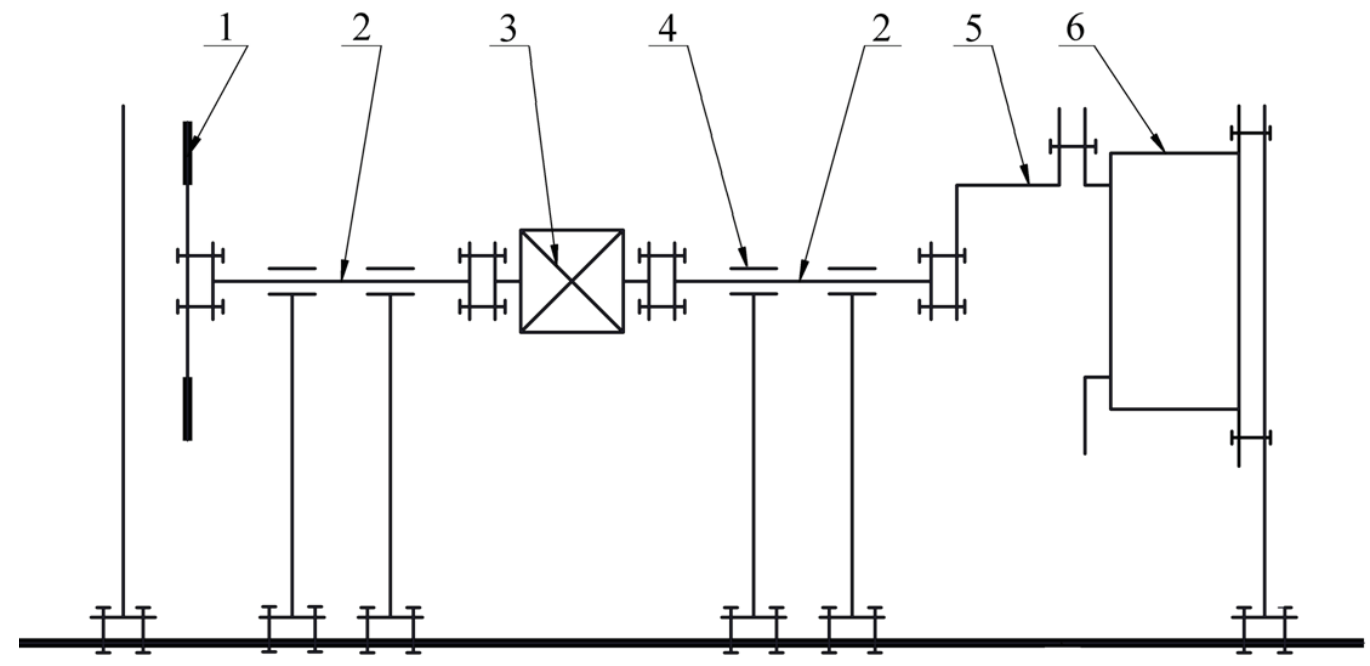

Figure 1: Installation scheme for measuring the output shaft torque of an electric rotary actuator with a reduction unit for an electromechanical orthosis of a lower limb exoskeleton

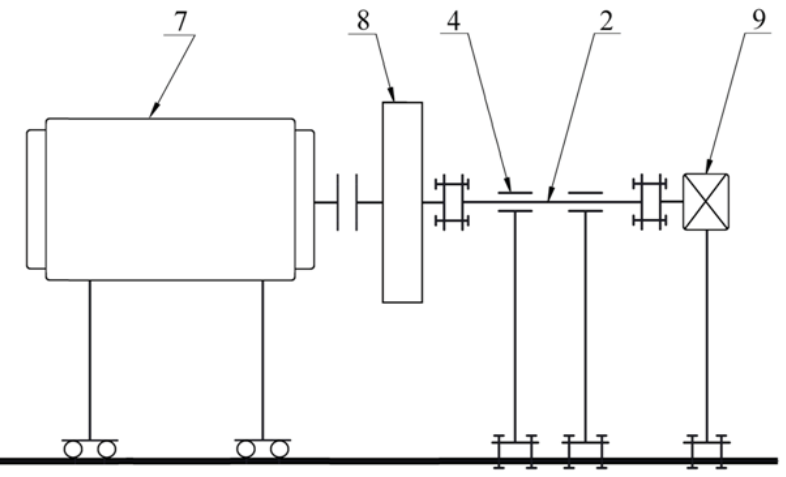

(a)

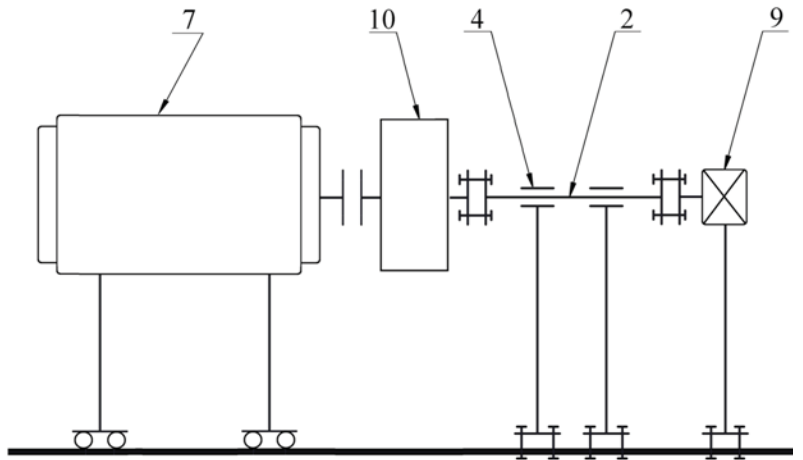

(b)

Figure 2: Scheme for determining the decelerating torque of mechanical losses in bearing assemblies using different rotary bodies having the equal weight and different values of the moment of inertia: (a) with a rotary body having the weight $m$ and the moment of inertia $J_{1}$; (b) with a rotary body having the weight $m$ and the moment of inertia $\mathrm{J}_{2}$ 


\section{Determination of the level of mechanical losses in bearing assemblies}

The second stage of the developed methodology for determining the efficiency of an electric rotary actuator with a reduction unit is associated with determining the braking torque caused by mechanical losses in the bearing units of the test bench, which allows identifying the output shaft torque without taking into account losses in them.

Fig. 2 shows the scheme for the implementation of the second stage of the proposed technique.

2 is a shaft of a bearing system; 4 is a bearing unit; 7 is a drive motor for accelerating the bearing system of rotating elements; 8 is a rotary body having the weight $m$ and the moment of inertia $J_{1} ; 9$ is an encoder; 10 is a rotary body having the weight $m$ and the moment of inertia $J_{2}$.

First, according to Fig. 2(a), we mount a rotary body 8 onto a shaft 2 . Using a drive motor 7 , we accelerate the presented system of rotating elements. When the rated rotational speed is reached, we disconnect the drive motor, and, with the help of an encoder 9, we register the angular deceleration values, $\varepsilon_{1}$, during the retardation of the rotating elements of the considered system from rated to zero rotational speed. The braking torque of mechanical losses in the bearing units 4 can be found according to the following equation:

$M_{B T B}=\left(J_{1}+J_{S R E}\right) \cdot \varepsilon_{1}=\left(J_{r e f}+J_{2}+J_{S R E}\right) \cdot \varepsilon_{1}$

Where, $J_{S R E}$ is the moment of inertia of the considered bearing system of rotating elements without rotary bodies 2 and $6 ; J_{\text {ref }}$ is the difference between the moments of inertia $J_{1}$ and $J_{2}$.

Then, the reference rotary body 8 is demounted, and the reference rotary body 10 is mounted on the shaft 2 (Fig. $2(b))$. With the help of the drive motor 7 , the system of rotating elements is accelerated. When the rated rotational speed is reached, the drive motor is disconnected. As a result, the rotational speed of the system decreases, and the resulting angular deceleration, $\varepsilon_{2}$, of the system of rotating elements with the reference rotary body 10 is registered.

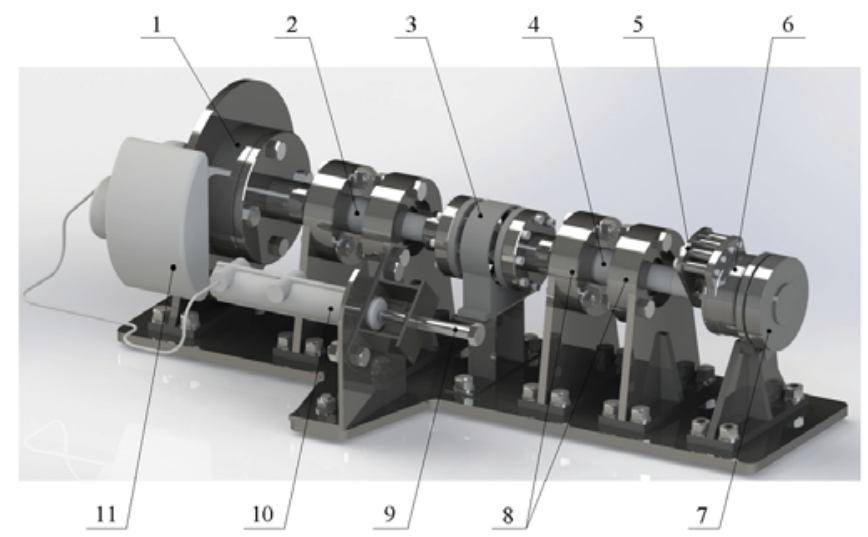

(a)
The braking torque of mechanical losses can be determined according to the following equation:

$M_{B T B}=\left(J_{2}+J_{S R E}\right) \cdot \varepsilon_{2}$

Since at the first and the second retardations the level of mechanical losses in bearing units 4 remains unchanged, we can equate the right-hand sides of (1) and (2) and find the value of $J_{S R E}+J_{2}$ according to the following equation:

$J_{S R E}+J_{2}=J_{r e f} \cdot \frac{\varepsilon_{1}}{\varepsilon_{2}-\varepsilon_{1}}$

Knowing $J_{S R E}, J_{1}$ and $J_{2}$, we can determine the decelerating torque $M_{\text {BTB }}$ caused by mechanical losses in the bearing units according to (1) or (2).

\section{Determination of the electric actuator efficiency for an electromechanical orthosis of a lower limb exoskeleton}

Having determined the output shaft torque of an electric rotary actuator 6 with a reduction unit, taking into account losses in the bearing assemblies $4, M_{T S}$, as well as the braking torque of losses in them, $M_{B T B}$, we can determine the efficiency of a reduction unit for an electromechanical orthosis of a lower limb exoskeleton according to the following equation:

$\eta=\frac{M_{T S}+M_{B T B}}{M_{S M}} \cdot 100 \%$

Where, $M_{S M}$ is the output shaft torque of an electric motor (specified in the certificate).

Knowing the values of the efficiency of a reduction unit and an electric motor, it is possible to calculate the efficiency of an electric rotary actuator for an electromechanical orthosis of a lower limb exoskeleton.

\section{EXPERIMENTAL SETUP}

To evaluate the proposed method for identifying the efficiency of an electric rotary actuator with a reducer for an electromechanical orthosis of a lower limb exoskeleton, test equipment and a test bench were developed (Fig. 3).

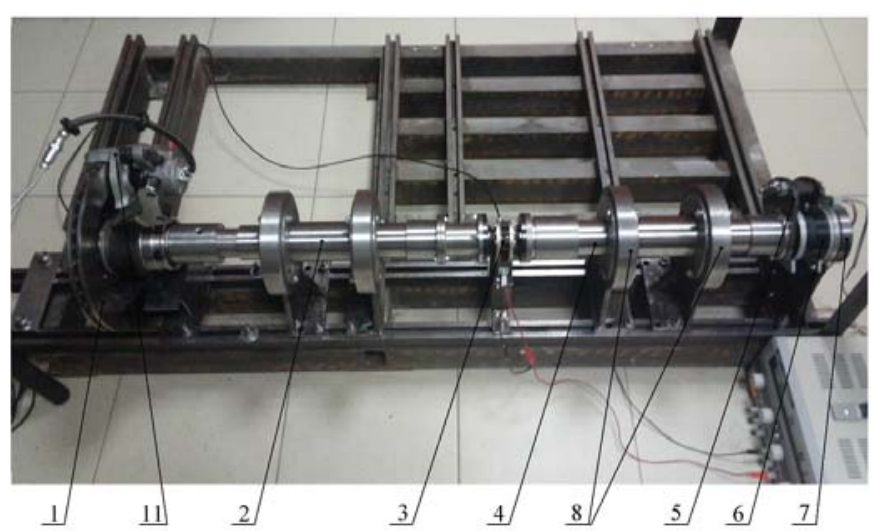

(b)

Figure 3: Test bench for determining the efficiency of an electric rotary actuator with a reduction unit for an electromechanical orthosis of a lower limb exoskeleton: (a) 3D-image; (b) photographic image 
The developed installation and test equipment have the following features: the rated output shaft torque of the electric rotary actuator is from 0.1 to $100 \mathrm{~N} \cdot \mathrm{m}$; rotational speed of the output shaft of the actuator is from 0 to 3,000 revolutions per minute; the height of the axis of rotation of the actuator is from 0.01 to 0.125 meters.

1 is a brake disk; 2 is a shaft of a brake disk; 3 is a torque sensor; 4 is a shaft of a bearing system; 5 is a special interconnecting link; 6 is a reduction unit of nonstandard design; 7 is an electric motor; 8 are bearing units; 9 is a brake control lever; 10 is a brake master cylinder; 11 is a brake caliper

The electric drive under test is driven by a flat motor Maxon Motors EC. These electric motors are characterized by high efficiency and compact flat design. The general view of the electric motor is shown in Fig. 4.

The parameters of the electric motor 7 are shown in Table 1.

Table 1: Electrical and mechanical parameters of a motor Maxon Motors EC 90 at rated voltage

\begin{tabular}{|l|c|}
\hline Parameter & Value \\
\hline Rated voltage [V] & 36 \\
\hline Idle speed [rev/min] & 3,120 \\
\hline Idle current [mA] & 348 \\
\hline Rated speed [rev/min] & 2,510 \\
\hline Rated torque [mN·m] & 560 \\
\hline Maximum efficiency [\%] & 87 \\
\hline
\end{tabular}

Based on the features of the electric motor, a high-performance control panel was created, which consisted of a debug board Escon Module Motherboard and a high-performance driver Escon Module $50 / 5$ made by Maxon Motors. In conjunction with feedback from Hall sensors integrated into the electric motor Maxon Motors EC 90, they ensure a reliable and flexible control of a synchronous electric actuator. For the driver Escon Module 50/5, a software Escon Studio was used, in which the module could be flexibly adjusted for any three-phase electric motor, for various feedback options and control algorithms (torque maintenance / speed maintenance). Programming was carried out after connecting Escon Module 50/5 to the USB port of PC and installing the necessary drivers for the system. The control panel of the motor consisted of a selector knob determining the direction of rotation, a resistor for adjusting the rotational speed of the electric motor, and the start and stop selector toggle switches. The motor power unit Mean Well HRPG-600-36 is rated for 36 volts.

Fig. 5 shows a general view of a reducer 6 for an electromechanical orthosis of a lower limb exoskeleton manufactured in the Mechatronic Systems Laboratory of Volga State University of Technology as part of the project called "Creating a high-tech production of a multifunctional robotic exoskeleton for medical purposes".

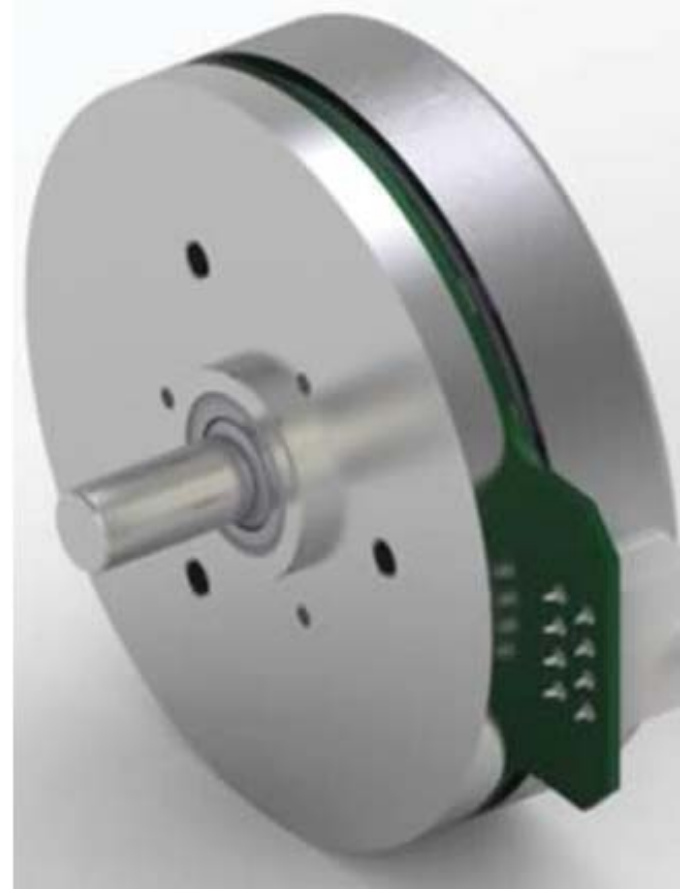

Figure 4: General view of a flat motor Maxon Motors EC 90

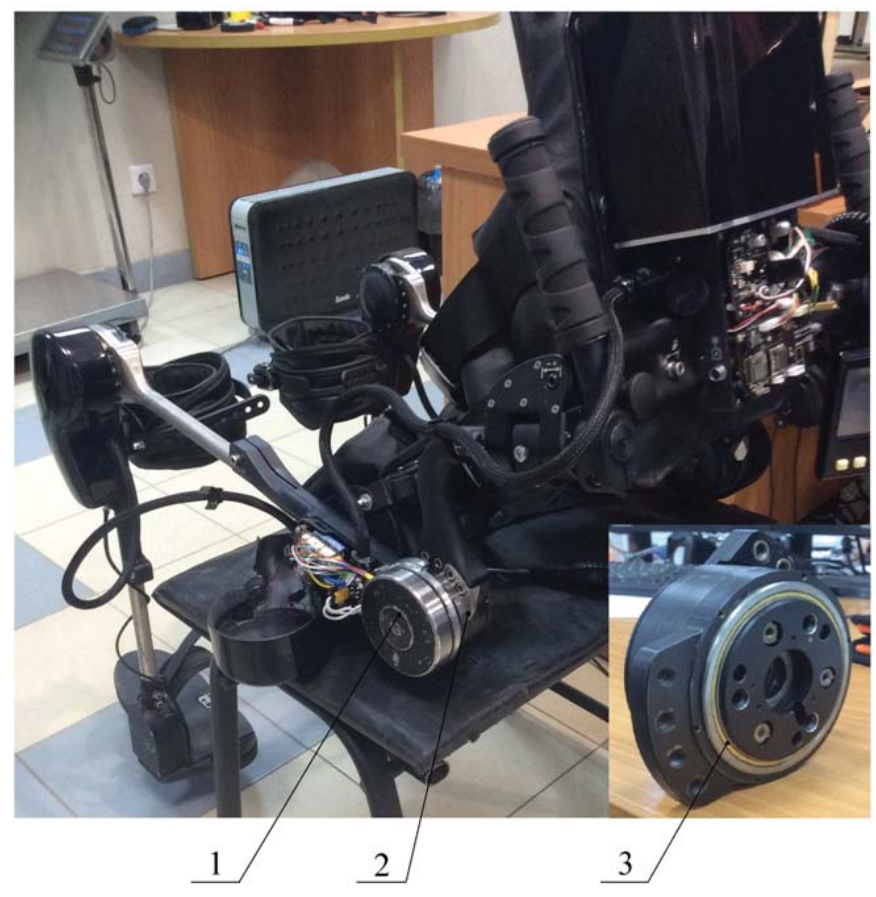

Figure 5: A reducer for an electromechanical orthosis of a lower limb exoskeleton

1 is a flat motor Maxon Motors EC 90 mounted on a lower limb exoskeleton; 2 is a reducer mounted on a lower limb exoskeleton; 3 is a general view of a reducer. Table 2 presents its main technical characteristics. 
Table 2: Technical characteristics of a reducer manufactured in the Mechatronic Systems Laboratory of Volga State University of Technology

\begin{tabular}{|l|c|}
\hline Parameter & Value \\
\hline Ratio & 114 \\
\hline Permissible torque [N.m] & 150 \\
\hline Rated torque [N·m] & 50 \\
\hline Rated rotational speed [rev/min] & 25 \\
\hline Rated DC voltage [V] & 36 \\
\hline Rated current [A] & 5 \\
\hline Working angle range [degrees] & 360 \\
\hline Life time [hours] & 5000 \\
\hline Operating ambient temperature $\left[{ }^{\circ} \mathrm{C}\right]$ & from -5 to +35 \\
\hline Weight [kg] & 2 \\
\hline
\end{tabular}

The determination of the torque and the angular acceleration of the tested electric rotary actuator was carried out using the torque sensor M40-100 manufactured by Tilkom, Minsk. Sensors of this type are designed to measure torque in a wide range of rated values: from $0.1 \mathrm{~N} \cdot \mathrm{m}$ to $100 \mathrm{~N} \cdot \mathrm{m}$. A microprocessor electronics module located on the rotor converts the signals of the strain gages into a digital code that is transmitted from the rotor to the stator via a noncontact telemetry communication channel. The main advantage of torque sensors M40 is the ability to measure both static and dynamic torque of positive and negative polarity, rotational speed and acceleration.

The moment of resistance on the output link of the electric rotary actuator was created using the front wheel brake mechanism from a vehicle of type VAZ 1111. The adjustment of the moment of resistance on the output link of the actuator was carried out by increasing or decreasing the pressure on a pusher of a brake mast cylinder 10 of VAZ 21083. The brake cylinder was connected to a caliper 11 with a metal tube.

To determine the level of losses in the bearing assemblies 8 installed in the developed test bench, a single-phase asynchronous electric motor AIR112MV6 of a power of
1.1 kilowatts with a rated rotational speed of 940 revolutions per minute and rotary bodies with reference values of inertia were used.

To identify the level of mechanical losses in the bearing units and the efficiency of the reducer, a measuring system was developed, which consisted of an encoder (torque sensor M40-100 with a function of registering angular accelerations), a measuring transducer (registrating unit) and a personal computer (PC) with the installed software for recording and analyzing the digital signal (Fig. 6).

\section{RESULTS AND DISCUSSION}

The reducers used for an electromechanical orthosis of a lower limb exoskeleton are produced in the laboratory "Mechatronic Systems" of Volga State University of Technology as part of the project called "Creating a hightech production of a multifunctional robotic exoskeleton for medical purposes." Existing instruments do not allow measuring the efficiency of electric rotary actuators with reduction units of non-standard design with a high accuracy, which impede the comparative analysis of existing methods and that developed towards the efficiency measurements of reducers being produced. Therefore, to evaluate the reliability of data obtained using the developed method and test equipment, in the experimental part, measurements of the output shaft torque of the electric motor Maxon Motors EC 90 without taking into account losses in the bearing units of the test bench were made, and the values obtained were compared with the values specified in the certificate of the motor.

To do this, the reducer was removed from the system of rotating masses, and the electric motor was connected with a special coupling to the shaft of the test bench (Fig. 7). Then, as described above, using the torque sensor M40-100, the torque of the electric motor, taking into account losses in the bearing assemblies, was measured.

After that, to determine the braking torque of mechanical losses in the bearing units of the test bench, measurements were carried out using the developed measuring system and the drive induction motor AIR112MV6 (Fig. 8).

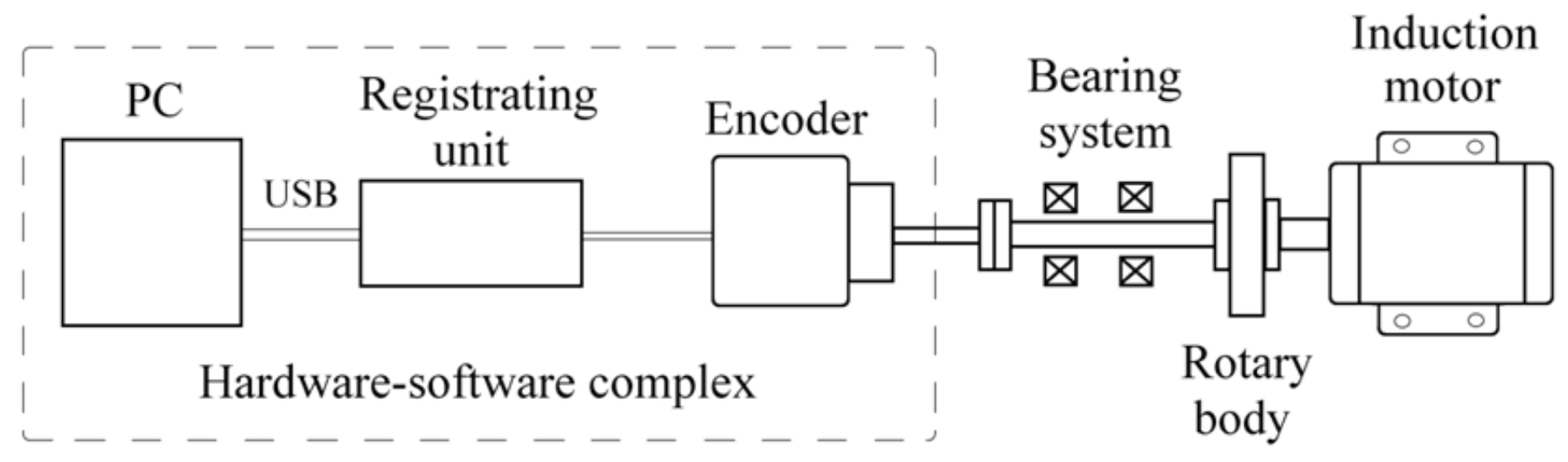

Figure 6: Scheme of hardware-software complex to measure the decelerating torque caused by mechanical losses in bearing units 


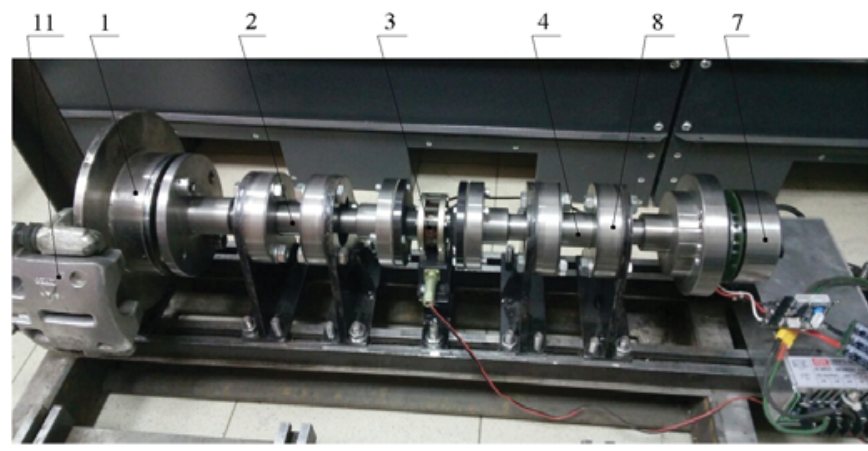

Figure 7: Test bench for determining the efficiency of the electric motor Maxon Motors EC 90 for an electromechanical orthosis of a lower limb exoskeleton In the experimental part of this work in the application of the developed technique 10 measurements were carried out, blunders were eliminated, random errors were determined and the average values were found.

1 is a brake disk; 2 is a shaft of a brake disk; 3 is a torque sensor; 4 is a shaft of a bearing system; 7 is an electric motor; 8 is a bearing unit; 11 is a brake caliper.

3 is a torque sensor M40-100 with a function of registering angular accelerations of a system of rotating elements; 8 are bearing units; 12 is an asynchronous electric motor of type AIR112MV6 (220/380 V), 4 kW, n = 940 rpm; 13 is a rotary body with the reference moment of inertia.

The results of the experiments are shown in Table 3.

Thus, according to the results obtained, the discrepancy between the output shaft torque values of the synchronous electric motor obtained using the developed method and the values given in its certificate, is about $1.2 \%$. This value slightly exceeds the total level of random and systematic errors of measurements with a tensometric

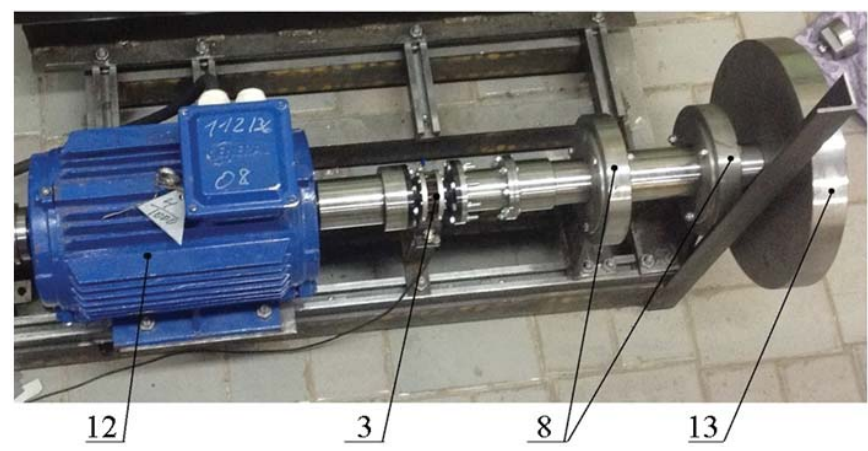

Figure 8: Installation for the experimental determination of the braking torque of mechanical losses in bearing units

torque sensor. The obtained results show the convergence of data sufficient for measuring the efficiency of reduction units and electric drives of non-standard design and conducting further research to improve their performance.

\section{CONCLUSIONS}

Based on the obtained results, we can conclude that the developed method allows identifying the efficiency of electric rotary actuators with non-standard reduction units without taking into account losses in the bearing units of test benches with high accuracy and with low level of time and labor costs.

The developed test equipment can be used to assess the efficiency of various reducers and non-standard electric drives not only at the stage of their production, but also during their operation and maintenance. At the same time, the use of existing engineering solutions, such as the car front wheel brake mechanism of VAZ 1111 and the car brake master cylinder of VAZ 21083

Table 3: The error in determining the output shaft torque of the electric motor Maxon Motors EC 90 using the developed method and test equipment

\begin{tabular}{|c|c|c|c|c|c|}
\hline Parameter & 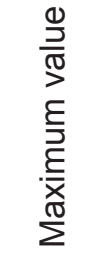 & 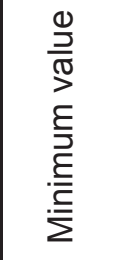 & $\begin{array}{l}\frac{0}{2} \\
\frac{1}{\pi} \\
\frac{1}{0} \\
\frac{\pi}{0} \\
\frac{\pi}{1}\end{array}$ & 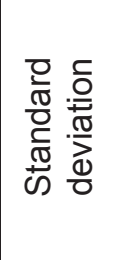 & 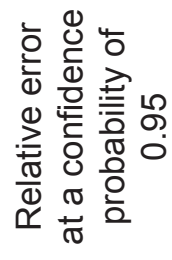 \\
\hline The torque determined by the torque sensor M40-100, MTS [mN·m] & 539.8 & 531.5 & 536.2 & 0.472 & 0.695 \\
\hline $\begin{array}{l}\text { The braking torque of mechanical losses in the bearing assemblies } \\
\text { determined using rotary bodies with reference moments of inertia } \\
\text { during retardation of the system of rotating elements, MBTB [mN.m] }\end{array}$ & 17.54 & 16.97 & 17.32 & 0.338 & 0.275 \\
\hline $\begin{array}{l}\text { Experimentally determined average torque of the electric motor } \\
\text { Maxon Motors EC } 90 \text { without taking into account losses in the } \\
\text { bearing assemblies }[\mathrm{mN} \cdot \mathrm{m}]\end{array}$ & - & - & 553.5 & - & - \\
\hline $\begin{array}{l}\text { The torque of the electric motor Maxon Motors EC } 90 \text { according to } \\
\text { the certificate data, MSM }[\mathrm{mN} \cdot \mathrm{m}]\end{array}$ & - & - & 560 & - & - \\
\hline $\begin{array}{l}\text { The discrepancy between the values obtained using the developed } \\
\text { method and specified in the certificate of the motor [\%] }\end{array}$ & - & - & 1.16 & - & - \\
\hline
\end{tabular}


monitoring the technical condition of reduction units and electric drives for exoskeletons.

The developed method can be used by companies producing reducers and electric rotary actuators of non-standard design. Having determined the level of mechanical losses in the bearing units of a test bench, it is possible to determine the effective characteristics of the manufactured products with high precision, as well as to conduct research on their improvement.

In the future, in order to develop this topic, it is assumed using the developed method and measurement instruments to pursue research on factors affecting the basic mechanical parameters of electric rotary actuators for various electromechanical parts of an exoskeleton in order to further improve their performance.

\section{ACKNOWLEDGEMENT}

The reported study was funded by Ministry of Education and Science of the Russian Federation according to the research project No. 03.G25.31.0261.

\section{REFERENCES}

1. Manna, S.K., \& Dubey, V.N. (2018). Comparative study of actuation systems for portable upper limb exoskeletons. Medical Engineering \& Physics, 60, 1-13. doi:10.1016/j.medengphy.2018.07.017

2. Arumugam, P., \& Kumar, A. [2016]. Design methods for compliant mechanisms used in new age industries: A review. Journal of Applied Engineering Science, 14(2), 223-232.

3. Ruiz-Olaya, A.F., Lopez-Delis, A., \& Rocha, A.F. (2019). Upper and Lower Extremity Exoskeletons. (Eds.), Handbook of Biomechatronics. Academic Press, Elsevier Inc., p. 283-317. DOI: 10.1016/ B978-0-12-812539-7.00011-8

4. Huysamen, K., Looze, M., Bosch, T., Ortiz, J., Toxiri, S., \& O'Sullivan, L.W.O. (2018). Assessment of an active industrial exoskeleton to aid dynamic lifting and lowering manual handling tasks. Applied Ergonomics, 68, 125-131. doi:10.1016/j.apergo.2017.11.004

5. O'Sullivan, L., Nugent, R., \& der Vorm, J. (2015). Standards for the safety of exoskeletons used by industrial workers performing manual handling activities: a contribution from the robo-mate project to their future development. Procedia Manufacturing, 3, 1418-1425. doi:10.1016/j.promfg.2015.07.306

6. Hyun, D.J., Park, H., Ha, T., Park, S., \& Jung, K. (2017). Biomechanical design of an agile, electricity-powered lower-limb exoskeleton for weight-bearing assistance. Robotics and Autonomous Systems, 95, 181-195. doi:10.1016/j.robot.2017.06.010

7. Moreno, J.C., Figueiredo, J., Pons, J.L. (2018). Exoskeletons for lower-limb rehabilitation. Colombo, R., Sanguineti, V. (Eds.), Rehabilitation Robotics. Academic Press, Elsevier Inc., p. 89-99. DOI: 10.1016/ B978-0-12-811995-2.00008-4.
8. Gasperini, G., Cannaviello, G., \& Guanziroli, E. (2018). Exoskeleton and end-effector robots for upper and lower limbs rehabilitation: narrative review. PM\&R, 10(9), 174-174. doi:10.1016/j. pmrj.2018.06.005

9. Hassani, W., Mohammed, S., Rifaï, H., \& Amirat, Y. (2014). Powered orthosis for lower limb movements assistance and rehabilitation. Control Engineering Practice, 26, 245-253. doi:10.1016/j.conengprac.2014.02.002

10. Chen, B., Ma, H., Qin, L.-Y., Gao, F., Chan, K.-M. \& et al. (2016). Recent developments and challenges of lower extremity exoskeletons. Journal of Orthopaedic Translation, 5, 26-37, DOI: 10.1016/j. jot.2015.09.007.

11. Aliman, N., Ramli, R., Haris, S.M. (2017). Design and development of lower limb exoskeletons: A survey. Robotics and Autonomous Systems, 95, 102116, DOI: 10.1016/j.robot.2017.05.013.

12. Veale, A.J., \& Xie, S.Q. (2016). Towards compliant and wearable robotic orthoses: A review of current and emerging actuator technologies. Medical Engineering \& Physics, 38(4), 317-325. doi:10.1016/j. medengphy.2016.01.010

13. Kim, H., Shin, Y.U., Kim, J. (2017). Design and locomotion control of a hydraulic lower extremity exoskeleton for mobility augmentation. Mechatronics, 46, 32-45, DOI: 10.1016/j.mechatronics.2017.06.009.

14. Ouyang, X., Ding, S., Fan, B., Li, P.Y., Yang, H. (2016). Development of a novel compact hydraulic power unit for the exoskeleton robot. Mechatronics, 38, 6875, DOI: 10.1016/j.mechatronics.2016.06.003.

15. Varghese, J., Akhil, V.M., Rajendrakumar, P.K., Sivanandan, K.S. (2017). A rotary pneumatic actuator for the actuation of the exoskeleton knee joint. Theoretical and Applied Mechanics Letters, 7(4), 222-230, DOI: 10.1016/j.taml.2017.08.002.

16. Long, Y., Du, Z., Chen, C., Wang, W., He, L. et al. (2017). Development and Analysis of an Electrically Actuated Lower Extremity Assistive Exoskeleton. Journal of Bionic Engineering, 14(2), 272-283, DOI: 10.1016/S1672-6529(16)60397-9.

17. Egorov, A., Kozlov, K., Belogusev, V. (2015). The method and instruments for induction motor mechanical parameters identification. International Journal of Applied Engineering Research, 10(17), 37685-37691.

18. Kotelnets, N., Akimova, N., Antonov, M. (2003). Tests, operation and maintenance of electric motors. Moscow: Akademiya.

19. Zhang, J., Cheah, C.C., Collins, S.H. (2017). Torque Control in Legged Locomotion. Sharbafi, M.A., Seyfarth, A. (Eds.), Bioinspired Legged Locomotion: Models, Concepts, Control and Applications. Butterworth Heinemann, Elsevier Inc., Oxford, p. 347-400. DOI: 10.1016/B978-0-12-803766-9.00007-5. 
20. Potapov, L., Yuferov, F. (1974). Measurements of torques and rotational speeds of micromotors. Moscow: Energiya.

21. Morris, A.S., Langari, R. (2016). Mass, Force, and Torque Measurement. Morris, A.S., Langari, R. (Eds.), Measurement and Instrumentation (Second Edition): Theory and Application. Academic Press, Elsevier Inc., p. 547-564. DOI: 10.1016/B978-0-12800884-3.00018-6.
22. Wegener, G., Andrae, J. (2007). Measurement uncertainty of torque measurements with rotating torque transducers in power test stands. Measurement, 40(7), 803-810, DOI: 10.1016/j.measurement.2006.08.001. 